\title{
Sentidos de saúde e modos de cuidar de si elaborados por homens usuários de Unidade Básica de Saúde - UBS
}

\author{
Significances of health and ways of taking care of oneself \\ prepared by male frequenters of Basic Health Units - UBS
}

Fabiane Aguiar Silva ${ }^{1}$ Iolete Ribeiro da Silva ${ }^{1}$
${ }^{1}$ Laboratório de

Desenvolvimento Humano, Faculdade de Psicologia, Universidade Federal do Amazonas. Av. General Rodrigo Octávio Jordão Ramos 3000 Campus Universitário St. Sul Bloco X, Coroado. 69.077000 Manaus AM Brasil. fabianeaguiarpsi@hotmail.com
Abstract The research sought to understand the significances of health and ways of taking care of oneself prepared by male frequenters of a Basic Health Unit-UBS in Manaus. The method used was qualitative research through semi-structured interviews with male frequenters and healthcare professionals of a UBS located in the outskirts of Manaus in the state of Amazonas. Data were analyzed using techniques of Thematization, Content Analysis and Significance Processing based on the Social Constructivist approach proposed by Spink. The research revealed the multifaceted issues of gender, which show that men "are not all equal," as there are various types of masculinities. The men interviewed in the health service showed that there are significances of health that they share with each other, but they also differ in many dimensions. The survey reflected that the plurality of significances of health and the ways of taking care of oneself confer a human character upon health and claim the proactive role of frequenters in the construction of a system of comprehensive health care. They point to indicators that can contribute to interventions in health for increasing the visibility of men in the health services and consequently the ability of the services to deal with them.

Key words Significances of health, Ways of taking care of oneself, Men, Basic Health Unit, Social constructionism
Resumo A pesquisa objetivou compreender os sentidos de saúde e modos de cuidar de si elaborados por homens usuários de Unidade Básica de Saúde (UBS) em Manaus. A proposta constituiu-se como pesquisa qualitativa que abordou, através de entrevistas semiestruturadas, homens usuários e profissionais de saúde de uma UBS localizada na periferia de Manaus, Amazonas. Os dados foram analisados através das técnicas de Tematização, Análise do Conteúdo e Processualidade do Sentido fundamentadas pela abordagem Construcionista Social discutida por Spink. A pesquisa revelou as multifaces da questão de gênero, as quais demonstram que os homens "não são todos iguais", existem masculinidades. Os homens entrevistados no serviço de saúde demonstraram que possuem sentidos de saúde que comungam entre si, mas que também se diferem por inúmeras dimensões. A pesquisa refletiu que a pluralidade dos sentidos de saúde e as performances de cuidado de si conferem à saúde o caráter humano e reivindicam o protagonismo dos usuários na construção do sistema de atenção integral à saúde. Apontam-se indicadores que podem contribuir para intervenções em saúde para a ampliação da visibilidade de homens nesses serviços e consequentemente a capacidade dos serviços em lidar com eles.

Palavras-chave Sentidos de saúde, Modos de cuidar de si, Homens, Unidade Básica de Saúde, Construcionismo social 


\section{Introdução}

As políticas de saúde no contexto brasileiro têm se desenvolvido recentemente quanto à percepção e uso das implicações de gênero na constituição de estratégias de atenção. Na tentativa de garantir a equidade de gênero no acesso aos serviços de saúde e a redução das estatísticas de patologias e morbidade, o governo federal através do Ministério da Saúde criou a Política Nacional de Atenção Integral à Saúde da Mulher no ano de 2004 e em seguida, a Política Nacional de Atenção Integral à Saúde do Homem, Ministério da Saú$\mathrm{de}^{1}$. Porém, pesquisas mostram a necessidade de reflexão e desenvolvimento de programas e campanhas que auxiliem na ampliação da perspectiva de gênero nos seguimentos da atenção integral à saúde. Esta pesquisa foi pensada para ajudar a suprir esta necessidade e não se trata apenas de distinguir as características da saúde por gênero, mas ampliar o conhecimento em direção à construção de políticas que garantam a cidadania pela universalização do direito à saúde, de forma que se considerem as peculiaridades gênero na relação com os serviços de saúde.

Os déficits demonstrados pelas estatísticas da saúde dos homens ilustram a importância de alinhar a perspectiva de gênero nas discussões sobre as políticas de saúde. Segundo dados do Portal da Saúde do Ministério da Saúde², os usuários do sexo masculino são as principais vítimas dos indicadores de mortalidade. No Brasil, apesar da população masculina ser inferior à feminina, prossegue-se apontando a amplitude de mortalidade do primeiro em relação ao segundo. De acordo com o portal, a cada três pessoas que morrem no Brasil, duas são homens. De cada cinco pessoas que morrem entre vinte a trinta anos, quatro são homens. Entre as principais causas estão: doenças do coração (entre elas infarto agudo do miocárdio), doenças cérebro vasculares e homicídios.

A situação adversa dos homens em relação aos serviços de saúde ilustra as distinções existentes nos indicadores de mortalidade entre os gêneros e demonstram uma política da saúde ainda insuficiente diante das demandas e necessidades apresentadas pelos homens.

Elegeu-se como fundamento aqui a proposta teórico-metodológica do Construcionista social que considera dinâmico o processo em que o sujeito atribui sentido a si e ao seu contexto de maneira em que tais dimensões se interagem mutuamente em um tempo histórico e social específico. A proposta enfatiza a coexistência de uma multiplicidade e de uma variedade de formas de vida dependentes das situações, valorizando uma busca pelo pluralismo. Na pesquisa científica, a abordagem Construcionista Social supera a noção de que a realidade possui um caráter estrutural e expande os olhares sobre a realidade.

Compreender a maneira como o gênero atribui significado, justapõe valores e estratégias, ordena e configura o que para eles é saúde e trata-se de uma fonte rica de dados que expressam a relação entre saúde e o cuidado de si refletidos pelos homens. A palavra saúde se inscreve em diferentes registros da experiência, seja esta real ou imaginária, de forma tal que a sua gramática e a sua sintaxe se precipitem em campos semânticos perpassados pela multiplicidade. A palavra saúde admite uma pluralidade de leituras possíveis, como decorrência necessária de que seria marcada por diferentes sentidos ${ }^{3}$.

O Cuidado de si foi abordado na pesquisa como uma tecnologia do eu, numa perspectiva ética, pode ser praticado e reconhecido na busca do autocuidado, significando a ampliação do governo de si, o exercício da liberdade, da decisão e, concomitantemente, implicando a redução dos espaços de sujeição e do governo pelos outros.

Quanto à reflexão do conceito de Gênero, esta se trata de uma discussão que instiga inúmeros conceitos marcados pelo tempo, história, cultura e movimentos sociais. Contudo, menciona-se Scott ${ }^{5}$ para pensar que gênero pode tratar-se de um elemento constitutivo das relações sociais, o qual está fundamentado nas diferenças percebidas entre os sexos, sendo também uma forma primeira de significar relações de poder. A autora conceitua gênero como categoria de análise, que se baseia na relação entre duas proposições: "gênero tanto é um elemento constitutivo das relações sociais fundadas sobre as diferenças percebidas entre os sexos, quanto uma maneira primária de significar relações de poder".

Dentro do aspecto de gênero existem peculiaridades elaboradas pela maneira como os grupos de homens lidam com o social enquanto constituem suas identidades. Discute-se que, na construção de gênero, muitos homens assumem comportamentos que interferem de forma a produzir riscos em suas condições de saúde. A performance de gênero também define a forma como os homens usam e percebem os seus corpos. Nas perspectivas de seus modelos de masculinidade, os homens muitas vezes assumem comportamentos considerados pouco saudáveis, os quais 
estão relacionados a um modelo de masculinidade idealizada, a hegemônica discutida por Connell ${ }^{6}$. Nesses modelos de masculinidade idealizada estão presentes as noções de invulnerabilidade e de comportamento de risco - como valores da cultura masculina - e a ideia de uma sexualidade instintiva e, portanto, incontrolável ${ }^{7}$.

Considera-se que, por aspectos sociais, históricos e culturais, os homens apresentam determinada resistência na procura por cuidados médicos e em atitudes preventivas com relação a problemas de saúde. Conforme diagnósticos, na maioria das vezes a população masculina procura os serviços de saúde por meio da atenção especializada, já com o problema de saúde detectado e em estágio de evolução. E ainda, apresentam dificuldades em dar prosseguimento e encerrar os processos terapêuticos aos quais se submetem ${ }^{2}$.

Desde 2008, a Política Nacional de Atenção Integral à Saúde do Homem alinhou-se com a Política Nacional de Atenção Básica - porta de entrada do Sistema Único de Saúde e com as estratégias de humanização em saúde. A partir do desenvolvimento via princípios do SUS, a política fomenta ações e serviços em redes e cuidados da saúde utilizando-se da Estratégia de Saúde da Família-PSF realizadas a partir de núcleos em Unidades Básicas de Saúde, as UBS. Estas são as unidades responsáveis pelo acesso da população aos diagnósticos de saúde em cada contexto, onde os serviços devem elaborar intervenções de assistência à saúde para favorecer a manutenção básica da saúde nos municípios brasileiros. A Política Nacional de Atenção Integral à Saúde do Homem efetivando-se nas UBS, que são portas de entrada da rede de saúde, pode contribuir para que as estratégias de humanização se articulem melhor com a busca pelo controle epidemiológico.

Existe a alternativa de se inserir opções que se aproximem ou ressignifiquem a saúde e o cuidado pelos homens. Sugere-se que no caso dos homens existem várias atitudes e comportamentos que podem se manifestar como necessidades em saúde, as quais no âmbito das UBS podem ser abordadas mais eficientemente. Para isso, é necessário que essa abordagem se dê numa dimensão em que se considerem essas situações como algo contextualizado nas relações socioculturais em que os homens e as mulheres vivem. É partindo dessa ideia que proponho lançar mão da perspectiva de gênero para alcançar um maior conhecimento das necessidades de saúde da população masculina ${ }^{7}$.

\section{Procedimentos metodológicos}

A pesquisa realizou-se de maneira qualitativa que possibilitou um tratamento de dados que mais se aproximou da dimensão subjetiva e social do participante. Elegeu-se uma Unidade Básica de Saúde - UBS/PA da zona leste de Manaus como campo de pesquisa por realizar o maior número de procedimentos na referida zona. Os serviços de saúde oferecidos pela UBS selecionados para o levantamento de informações partiram das atividades especializadas voltadas para homens e serviços sem tal especificidade, além disso, outros que foram incluídos durante a pesquisa.

Os participantes foram seis homens adultos usuários e quatro profissionais da UBS. Os profissionais foram: enfermeiro, técnico de enfermagem, administrador e assistente social. O procedimento de levantamento dos dados constituiu-se a partir de duas entrevistas semiestruturadas, sendo uma para os usuários e uma para os profissionais. Utilizaram-se também diários de campo para o registro das situações observadas e/ou experimentadas durante o desenvolvimento da atividade de pesquisa.

Os dados levantados foram analisados através das técnicas de Tematização, Análise do Conteúdo ${ }^{8}$ e Processualidade do Sentido fundamentada pela abordagem Construcionista Social discutida por Spink 9 .

\section{Resultados e discussão}

A presente pesquisa apresenta os discursos dos participantes a partir dos sentidos de saúde elaborados pelos mesmos e as performances de gênero dos homens usuários, além de suas relações com os serviços de saúde. De maneira a considerarem-se as particularidades representadas pelas performances masculinas diversas, evidenciou-se o trabalho com o discurso de cada um dos usuários.

Os seis usuários buscavam na UBS serviços como atendimento clínico (com médicos clínicos gerais bem como, com especialistas em ortopedia, oftalmologia e psiquiatria) e exames. Apresentaram idades entre vinte e três a cinquenta anos, profissões autônomas, residiam na periferia da cidade, religião em sua maioria católica e evangélica, a maior parte dos homens possuíam união estável com suas parceiras, escolaridade média, nascidos nos estados do Pará e Amazonas, média de dois a três filhos e a renda mensal comum correspondia a dois e três salários mínimos. 


\section{Sentidos de Saúde}

O referido eixo de significação constituiu-se a partir de perguntas que investigaram os sentidos de saúde. O sentido foi obtido através de significações que compuseram um repertório dos discursos sobre saúde, ser saudável, estar saudável e avaliações sobre o estado de saúde. Os sentidos foram elencados (Quadro 1) e discutidos segundo suas particularidades, bem como, suas relações entre si.

\section{A saúde como autonomia física e psicológica}

Dentre as concepções acerca do termo autonomia, pode-se considerar a recorrência das funções de liberdade e capacidade do indivíduo para decidir sobre suas próprias ações. Toma-se o conceito explicitado por Fleury-Teixeira et al. ${ }^{10}$, a ideia de autonomia (auto $=$ próprio, nomos $=$ norma, regra, lei) conduz o pensamento imediatamente à ideia de liberdade e de capacidade de exercício ativo de si, da livre decisão dos indivíduos sobre suas próprias ações e às possibilidades e capacidades para construírem sua trajetória na vida. Sintetizam-se, enfim, na prescrição: "sê senhor de si". O sentido de saúde construído por Hércules compreendia a saúde como o que habilita o homem para a vivência da autonomia a partir da conjuntura física e psicológica. A partir da saúde o homem pode ser o senhor de si e desempenhar sua liberdade utilizando-se de suas condições fisiológica e psicológica saudáveis.

\section{Preocupações e remédios não compõem a saúde, atestam a ausência desta}

De acordo com Hércules, os condicionamentos de sua saúde à ingestão de remédios e às preocupações cotidianas significavam a ausência da saúde. O usuário relacionou remédios e preocupações à ausência de saúde, ou seja, ingerir medicações e viver os problemas como aspectos que atestam a ausência da saúde e podem, de acordo com o tópico discutido anteriormente, comprometer a autonomia. $\mathrm{O}$ significado de saúde que relacionou medicamentos e preocupações à ausência de saúde pode fazer-se contributivo a diversas discussões. Destaca-se o fato de determinadas masculinidades não realizarem o consumo de medicações como prescrito, ou mesmo não consumirem.

Quadro 1. Sentidos de Saúde.

\begin{tabular}{|l|c|l|}
\hline Usuário & \multicolumn{1}{|c|}{ Sentido de Saúde } & \multicolumn{1}{c|}{ Discussão } \\
\hline Hércules & $\begin{array}{c}\text { "Saúde é o cara tá bom do corpo e do } \\
\text { psicológico. Ai ele consegue trabalhar, ficar de } \\
\text { boa...ai ele num fica agoniado com a vida". }\end{array}$ & $\begin{array}{l}\text { - A saúde como autonomia física e } \\
\text { psicológica; } \\
\text { - Preocupações e remédios não compõem a } \\
\text { saúde, atestam a ausência desta. }\end{array}$ \\
\hline Aquiles & $\begin{array}{c}\text { "Saúde é uma coisa importante... como você } \\
\text { taí com seu juízo limpo... e eu tô conversando } \\
\text { com você aqui, mas tô com outro } \\
\text { pensamento... tô pensando no meu trabalho" }\end{array}$ & $\begin{array}{l}\text { - A saúde é a regulação do psiquismo através } \\
\text { da dualidade biológico-psicológico. }\end{array}$ \\
\hline Deon & $\begin{array}{c}\text { "Olha... saúde pra mim é tudo. Tudo! Não } \\
\text { adianta ter dinheiro... muito dinheiro... se } \\
\text { num tem saúde num tem nada!" }\end{array}$ & $\begin{array}{l}\text { - A saúde significada a partir da construção } \\
\text { social da masculinidade pelo trabalho. }\end{array}$ \\
\hline Minos & $\begin{array}{c}\text { "Saúde é ... viver sem dores né?!" } \\
\text { trabalhar ai eu tô com saúde" }\end{array}$ & $\begin{array}{l}\text { - Saúde é ausência de dor, bem como, } \\
\text { estética/rejuvenescimento/potência sexual/ } \\
\text { disposição física. }\end{array}$ \\
\hline Perseu & $\begin{array}{c}\text { "Ah! Saúde é tudo... se a gente não tiver } \\
\text { saúde... a gente num tá feliz né?!" }\end{array}$ & $\begin{array}{l}\text { - A saúde como a felicidade de não ter } \\
\text { problemas (doenças). }\end{array}$ \\
\hline Heitor & $\begin{array}{c}\text { "Saúde é eu poder trabalhar. Eu podendo } \\
\text { arrio pra qualquer dorzinha". }\end{array}$ \\
\hline
\end{tabular}


A saúde é a regulação do psiquismo através do humor e das relações sociais: a superação da dualidade biológico-psicológico

Compreendeu-se que Aquiles produziu um sentido de saúde fundamentado na sua situação psíquica a partir do humor e de suas relações. Desta feita, as relações sociais produzidas no trabalho, na família e no dia-a-dia em geral, configuraram seu psiquismo para a vivência temporária de uma saúde ou não e o seu estado psíquico também regularia uma vivência saudável destas relações. O sentido que foi apresentado pelo usuário demonstrou uma saúde regulada também pelo psíquico e não necessariamente somente no aspecto biológico ou natural.

O referido sentido elaborado por Aquiles ressaltou a discussão: seria impossível enunciar um sentido unívoco para a palavra saúde? Ou pelo contrário, a concepção de saúde seria marcada pela pluralidade de sentidos, na medida em que são variados os contextos sociais, históricos e linguísticos nos quais esta palavra é empregada? Neste contexto, a palavra se inscreve em diferentes registros da experiência, seja esta real ou imaginária. Portanto, a primeira assunção a ser feita aqui é o reconhecimento inequívoco de que a palavra saúde admite uma pluralidade de leituras possíveis, como decorrência necessária de que seria marcada por diferentes sentidos ${ }^{3}$.

Aquiles anunciou um sentido que representa uma dentre as diversas dimensões vivenciadas pelos homens. O discurso do mesmo não se compatibiliza com alguns sentidos de masculinidade hegemônica. E diferente do sentido de funcionalidade corporal, Aquiles apontou o sentido de uma saúde das relações que pode apresentar-se no biológico. Desta feita, trata-se de um sentido desprovido da dualidade biológico-psicológico que ressalta a integralidade e a inexistência de fronteiras entre tais constituintes do ser humano.

\section{A saúde significada a partir da construção social da masculinidade pelo trabalho}

Deon construiu um sentido de saúde a partir de suas relações sociais fundamentadas no trabalho. A saúde como mantenedora da função social do trabalho pode ser compreendida a partir dos referenciais de socialização masculina. No essencialismo ocidental, onde elementos de caráter cultural mesclam-se aos de caráter natural, o homem é apresentado como provedor da família e protetor da mulher e das crianças. E ainda, no essencialismo cultural existe o raciocínio conservador de que falhar nas tarefas femininas não acarreta nenhum dano maior para a comunidade; nos assuntos masculinos, pode significar a diferença entre manutenção ou extinção da comunidade. Não é questionado em momento algum o fato de serem os homens os responsáveis pelas "tarefas essenciais". Mediante tais atributos da masculinidade, compreende-se que o trabalho se constitui como uma identidade masculina construída pelas relações na história das sociedades ${ }^{11}$.

\section{Saúde é ausência de dor, bem como, estética/rejuvenescimento/potência sexual/ disposição física}

Minos também apresentou um sentido de saúde como ausência de dor, mas a relacionou a outros aspectos imprescindíveis para o mesmo. As dimensões estética/rejuvenescimento/potência sexual/disposição física significaram para Minos o sentido de saúde, o participante explanou que tais aspectos interagem com a dimensão ausência de dor e vice-versa. Minos apresentou à pesquisa um sentido de saúde que o Construcionismo Social ressalta como não mais a vinculação crua de necessidades como um quebra-cabeça, mas o próprio sentido como uma construção de necessidades a partir das relações em que o homem produz. Desta feita, Minos apresentou em seu discurso a dinâmica da construção de um sentido, onde os significados não apenas se vinculam, desenvolvem-se simbioticamente. E estudar os sentidos de saúde tratou-se de um trabalho de questionar os conceitos de saúde pré-estabelecidos e difundidos pelas instituições de saúde pública e coletiva. E nesta pesquisa, demonstra-se, a partir dos sentidos estudados, que enquanto as instituições de saúde permanecerem utilizando apenas parâmetros de saúde podem continuar não acessando os usuários, principalmente aqueles mais "invisíveis", os homens.

E quanto à possibilidade de abordar a saúde como algo construído por subjetivações indivigrupais, questiona-se o conceito de saúde da Organização Mundial de Saúde (OMS), na qual trata-se de um completo estado de bem-estar físico, mental e social e não apenas a ausência de doença ou enfermidade. E busca-se considerar que a saúde das pessoas deve ser encarada como um assunto ligado às próprias pessoas e alheia a qualquer padronização e a qualquer determinação fixa e pré-estabelecida, de modo a impedir diferentes interpretações e legitimações, a priori, de controle e governo dos outros ${ }^{12}$. 


\section{A saúde como a felicidade de não ter problemas (doenças)}

Perseu atribuiu à saúde o sentido da felicidade em não ter problemas de saúde, ou seja, uma satisfação de viver ao passo que estiver sem doenças. O sentido apresentado pelo participante pode ter se remetido à tentativa do governo federal em realizar a intersetorialidade para a atenção integral em saúde, ou seja, a saúde não tem sido abordada isoladamente, mas vinculada à educação, lazer, segurança, meio ambiente, dentre outros. O termo intersetorialidade aqui discutido se trata do processo de construção compartilhada, em que os diversos setores envolvidos são tocados por saberes, linguagens e modos de fazer que não lhes são usuais, pois pertencem ou se localizam no núcleo da atividade de seus parceiros. A intersetorialidade implica a existência de algum grau de abertura em cada setor envolvido para dialogar, estabelecendo vínculos de corresponsabilidade e cogestão pela melhoria da qualidade de vida da população ${ }^{13}$.

Além da discussão sobre a pluralidade dos sentidos e não apenas conceitos de saúde, Perseu destacou com o significado "feliz" a existência de uma subjetivação que fundamenta a saúde. O usuário demonstrou em seu discurso que a satisfação de viver seria algo psicossocial, assim, ao passo que as políticas de saúde ainda buscarem ampliar o conceito de saúde, poderiam estar continuando a impor a saúde e não necessariamente construindo-a com os usuários. Um primeiro passo poderia ser a promoção da saúde é um campo teórico-prático-político que em sua composição com os conceitos e as posições do Movimento da Reforma Sanitária delineia-se como uma política que deve percorrer o conjunto das ações e projetos em saúde, apresentando-se em todos os níveis de complexidade da gestão e da atenção do sistema de saúde. Tal política precisa deslocar o olhar e a escuta dos profissionais de saúde da doença para os sujeitos em sua potência de criação da própria vida, objetivando a produção de coeficientes crescentes de autonomia durante o processo do cuidado à saúde. Uma política, portanto, comprometida com serviços e ações de saúde que coloquem os sujeitos usuários e profissionais de saúde -, como protagonistas na organização do processo produtivo em saúde, entendendo que aí se produz saúde, sujeitos, mundo ${ }^{13}$.

\section{Masculinidade hegemônica: \\ Eu não me arrio pra qualquer dorzinha}

Heitor apresentou um sentido de saúde relacionado à sua função social do trabalho, destacando que trabalhar chegaria a ser um "divertimento”. O usuário ressaltou em seu discurso a satisfação em poder trabalhar e ter saúde para tal.

A saúde, segundo Heitor, seria a condição para que a satisfação de trabalhar fosse mantida. O sentido produzido por Heitor expressou a necessidade do mesmo em não se prostrar para a dor, pois aderir à dor seria uma maneira de não conseguir cumprir sua função social de gênero e consequentemente, não mais se satisfazer. Os demais usuários e com particular intensidade, Heitor, apresentaram a função social do trabalho como uma dimensão que garantiria ao homem manter-se como provedor, forte, estabilizado, dentre outros adjetivos, porém, a mesma função poderia ser produzida pelos mesmos também como uma exigência de indestrutividade e obstinação em função do status másculo que não pode assemelhar-se ao femíneo.

Tal processo de subjetivação pode remeter-se ao processo de socialização masculina a partir do delineio da Masculinidade Hegemônica. Pesquisas recentes têm discutido sobre masculinidade como uma construção de gênero. Esses estudos, em geral, buscam identificar e analisar como os homens atualizam, em seu cotidiano, o modelo hegemônico de masculinidade, considerando as matrizes culturais e históricas em que interagem e se desenvolvem socialmente. Nesse sentido, de uma forma geral, os homens são educados, desde cedo, para responder a expectativas sociais de modo proativo, em que o risco não é algo a ser evitado, mas superado cotidianamente. A noção de autocuidado dá lugar a um estilo de vida autodestrutivo, a uma vida, em diversos sentidos, vulnerável. Com isso, muitos homens em condições sociais diversas também enfrentam, cotidianamente, a impossibilidade e a obrigação de responder ao modelo hegemônico de masculinidade, colocando-se em posições hierárquicas desfavoráveis ${ }^{14}$.

A masculinidade representada por Heitor trata-se de uma entre várias vivenciadas por outros homens em suas relações. Abordar os sentidos de saúde apresenta os usuários não apenas como pacientes, mas como homens (infantis, jovens e/ ou adultos), maridos, pais, trabalhadores, estudantes, amantes, atletas de final de semana e infinitas outras dimensões que se desenvolvem nas relações. Desta feita, dar voz e vez ao que aos 
usuários dizem sobre saúde pode ser um passo para a reflexão sobre as políticas de saúde estruturadas e executadas até então no social.

\section{Por que compreender os sentidos de saúde?}

Evidenciam-se os sentidos de forma a questionar o caráter universal do conceito de saúde adotado pelas políticas públicas. Propõe-se a construção cotidiana de um sistema de saúde sob a estratégia de aproximação aos sentidos da comunidade que atende, considerando as particularidades e ressaltando as questões de gênero ao dar voz aos homens, caracterizados como invisíveis. Pode ser a questão de gênero, o alerta de que não se trabalham os sentidos na saúde pública básica.

A construção em saúde caracteriza-se principalmente por seu processo e em tempos contemporâneos as políticas de saúde e a situação da própria saúde no Brasil pode estar entrando em outra etapa do processo de reflexão crítica e desenvolvimento da atenção básica.

\section{Modos de cuidar de si}

A propósito metodológico, procurou-se descrever os modos de cuidar de si no objetivo de relacioná-los aos sentidos de saúde e demonstrar a complexidade dinâmica das relações dos homens com os serviços de saúde. Deste modo, apresentam-se no Quadro 2 os modos de cuidar de si descritos pelos homens entrevistados e ressaltam-se suas estratégias de cuidado.

\section{Por que compreender os modos de cuidar de si?}

Os modos de cuidar de si elaborados pelos usuários perpassam pela questão de gênero e traz à tona reflexões sobre a relação que os serviços de saúde estabelecem com o usuário e vice-versa. Aspectos como autonomia, desconforto com procedimentos clínicos invasivos e/ou constrangedores, função social do trabalho, estética e autoestima na relação, protagonismo e a pluralidade no sentido do cuidado fundamentaram os discursos dos entrevistados em suas estratégias de cuidado de si e produziram reflexões impres-

Quadro 2. Modos de cuidar de si.

\begin{tabular}{|c|c|c|}
\hline Usuário & Modo de cuidar de si & Estratégias \\
\hline Hércules & O cuidado "do jeito que dá" & Joga bola e vai "na farmácia". \\
\hline Aquiles & $\begin{array}{c}\text { Cuida "bem pouco" porque tem "medo de } \\
\text { pegar injeção" }\end{array}$ & $\begin{array}{l}\text { Tem relações sexuais somente com a } \\
\text { "pessoa certa"; } \\
\text { Toma cuidados para não ficar "banguelo". }\end{array}$ \\
\hline Deon & $\begin{array}{c}\text { "a gente como homem tem mais preocupação } \\
\text { com o trabalho" }\end{array}$ & $\begin{array}{c}\text { Ingere os remédios na "hora certa"; } \\
\text { Não fuma. }\end{array}$ \\
\hline Minos & $\begin{array}{l}\text { "eu sempre me cuidei... gostei de me arrumar } \\
{[\ldots . .] \text { porque num é só a mulher... gente tem }} \\
\text { que... se cuidar também pra mulher }[\ldots . .] \text { assim } \\
\text { como a mulher se cuida pro homem... o } \\
\text { homem também que se cuidar pra mulher..." }\end{array}$ & $\begin{array}{l}\text { Consome alimentos naturais; } \\
\text { Dorme e faz exercícios laborais na empresa. } \\
\text { Passa "cremes" no corpo. }\end{array}$ \\
\hline Perseu & $\begin{array}{l}\text { Cuida da saúde "num bebo... num } \\
\text { fumo...é...num saio à noite...num tenho } \\
\text { relacionamento com ninguém...só com a } \\
\text { minha esposa }[. . .] \text { num faço extravagância, } \\
\text { né?!" }\end{array}$ & $\begin{array}{l}\text { Faz exames e reutiliza prescrições para } \\
\text { doenças recorrentes. } \\
\text { Faz exercícios físicos “trabalhando”. }\end{array}$ \\
\hline Heitor & Cuida da saúde por "conta própria" & $\begin{array}{l}\text { Consome "remédios caseiros". } \\
\text { Se o médico manda tomar } 2 \text { vezes ao dia, o } \\
\text { mesmo toma } 3 \text { vezes. }\end{array}$ \\
\hline
\end{tabular}


cindíveis a propostas de políticas e intervenções de saúde pautadas na questão de gênero.

Cuidar do "do jeito que dá" ou "bem pouco" porque tem "medo de pegar injeção" e apesar de "a gente como homem tem mais preocupação com o trabalho" isso não impede necessariamente de "eu sempre me cuidei... gostei de me arrumar [...] porque num é só a mulher... gente tem que... se cuidar também pra mulher [...] assim como a mulher se cuida pro homem... o homem também que se cuidar pra mulher...", mas existe a possibilidade de não ter que cuidar da saúde se "num bebo... num fumo... é... num saio à noite... num tenho relacionamento com ninguém... só com a minha esposa [...] num faço extravagância, né?!". Esses sentidos de cuidado podem significar o cuidado autônomo, aquele por "conta própria", o que quem sabe seja o que eles julgam como protagonismo. Construiu-se um mosaico com os discursos dos entrevistados na tentativa de relacionar os sentidos de cuidados que os mesmos produzem e a maneira como os desempenham. E percebeu-se que os significados se perpassam a partir dos aspectos de autonomia, gênero e saúde.

Refletiu-se na presente pesquisa que buscar os motivos pelos quais os homens podem "não cuidar" da saúde trata-se de um caminho para o acesso à forma que eles elegem de cuidar. Portanto, os dados que atestam que o homem não cuida da saúde podem ser refletidos se tais cuidados não se passam apenas de parâmetros pré-estabelecidos de saúde, os quais esses homens podem não conseguir se enquadrar, mas apesar disso, da maneira deles, procuram realizar seus próprios cuidados a partir do sentido que elaboram sobre a saúde.

Por muito tempo as pesquisas em Ciências Humanas e Sociais e as ações políticas em saúde têm relacionado o conceito de homem ao genérico ser humano e o conceito de gênero às mulheres. Hoje, constata-se que o conhecimento sobre práticas sociais masculinas pode contribuir para ampliar o impacto de programas voltados à prevenção de doenças sexualmente transmissíveis, ao controle da violência de gênero, à saúde das crianças, das mulheres e, principalmente, dos próprios homens ${ }^{14}$.

Os homens protagonistas desta pesquisa afirmam seus cuidados de saúde a partir do que julgam ser a saúde, apesar dos fatores de gênero agravantes como: a masculinidade hegemônica, as dificuldades de negociação com a instituição trabalho, o medo de agulhas ou a vergonha de andar com fezes dentro de um vidro, à priorida- de ao autocontrole e à impaciência com a morosidade e burocracia da rede de saúde que justificam suas buscas apenas episódicas às unidades de saúde. Os mesmos constroem sentidos de qualidade de vida baseados na realidade em que vivem e não necessariamente no que é estipulado pelos serviços.

A discussão desta pesquisa baseia-se na possibilidade de ampliar a produção de conhecimento sob a questão de gênero, saúde e masculinidades. Além das discussões sobre a masculinidade, necessita-se ampliar os estudos sobre as potencialidades e mobilizações masculinas na manutenção de suas saúdes e na obtenção de qualidade de vida. Para tal, faz-se imprescindível ouvir os homens e suas demandas, bem como suas potencialidades na busca pela saúde nos serviços públicos e na promoção de suas próprias saúdes.

\section{A relação com os serviços de saúde...}

Ao atentar-se para a relação dos homens com os serviços de saúde é possível elencar recorrências baseadas nas particularidades das relações estabelecidas por eles. Percebe-se através das descrições de cada um dos entrevistados no Quadro 3 que os motivos de buscar episodicamente a UBS são distintos e também semelhantes.

Dentre os discursos dos entrevistados, percebeu-se que além do aspecto de gênero, as carências na saúde pública brasileira influem na performance da relação do homem com o serviço de saúde. "Impedimentos" como o trabalho e o sentido de que um homem só deve procurar o serviço de saúde quando acontecer emergências caracterizam a questão de gênero na relação com o serviço de saúde. Porém, o anseio frustrado de fazer exames e não conseguir, a ausência de acolhimento nas UBS, o déficit de profissionais, bem como de profissionais especializados e qualificados, a ausência do aspecto integrativo pela UBS em relação aos usuários, a burocracia na rede de atenção à saúde e a morosidade no oferecimento do serviço tratam-se de queixas unânimes entre os entrevistados que as mencionam como agravantes em suas dificuldades de buscar os serviços públicos de saúde.

Entre os homens que se cuidam de acordo com o prescrito e os que se cuidam orientados prioritariamente por seus sentidos de saúde, ambos se queixam da ausência de um atendimento mais satisfatório. Desejam um serviço que ofereça informações, atenção e profissionais em quantidade básica para atender à demanda da comunidade, bem como profissionais especiali- 
Quadro 3. Relação com os serviços de saúde.

\begin{tabular}{|l|l|}
\hline Usuário & \multicolumn{1}{c|}{ Relação com os Serviços de Saúde } \\
\hline Hércules & $\begin{array}{l}\text { "A gente vem porque precisa mesmo... mas se for no caso de uma emergência mesmo... a } \\
\text { gente morre". }\end{array}$ \\
\hline Aquiles & $\begin{array}{l}\text { As UBS “não conversam com as pessoas [...] o médico passa um remédio e por isso fica" e um } \\
\text { serviço de saúde ajudaria o usuário ao "Ver a saúde não só enfermo..." }\end{array}$ \\
\hline Deon & $\begin{array}{l}\text { O serviço de saúde é um "vem, vai,volta...”, porém deveria "tentar... procurar ver o problema } \\
\text { que tá acontecendo... procurar vê o que eu tô sentindo seria bom assim...” }\end{array}$ \\
\hline Minos & $\begin{array}{l}\text { O serviço de saúde deveria "colocar pessoas mais qualificada, principalmente na parte de } \\
\text { recepção, de atendimento... a pessoa tem que tá informada pra saber informar... pra } \\
\text { comunidade que vem buscar a saúde...” }\end{array}$ \\
\hline Perseu & $\begin{array}{l}\text { "Eu vou às vezes... eu vou na UBS aqui... quando tá muito difícil aqui eu vou particular". Um } \\
\text { serviço de saúde poderia ajudar se oferecesse "Facilitação! Já que existe um programa de saúde } \\
\text { pra ajudar as pessoas, devia ser mais flexível, mais aberto, mais com vontade de ajudar...” }\end{array}$ \\
\hline Heitor & $\begin{array}{l}\text { "O trabalho impede muito a gente de procurar uma unidade de saúde e... que a gente vai } \\
\text { muitas veze e não consegue fazer muito os exames... ou se consultar... tem que passar um } \\
\text { mês, dois mês pra poder fazer um exame...” }\end{array}$ \\
\hline
\end{tabular}

zados e qualificados na equipe multiprofissional necessária ao atendimento integral de saúde.

\section{Considerações finais}

A pesquisa revelou as multifaces expressadas pela questão de gênero as quais demonstram que os homens "não são todos iguais", existem masculinidades. Os homens entrevistados no contexto de busca do serviço de saúde demonstraram que possuem sentidos de saúde que comungam entre si, mas que também se diferem por inúmeras variáveis. Tanto os sentidos de saúde como os modos de cuidar de si expressados por eles não são totalmente dissociados, mas também não podem ser considerados unânimes por generalizações. E tomando a contribuição de Nolasco $^{15}$, afirma-se que a narrativa do senso comum que parte da premissa de que "homem é tudo igual" não dá conta de toda a diversidade da experiência masculina. E ser homem não trata somente da experiência subjetiva e pessoal do sexo masculino. Trata, também, de uma experiência que se constrói social e culturalmente, datada historicamente, permeada de códigos, práticas e representações que são produzidos em cada sociedade, e que conforma certo modelo hegemônico de homem, com um leque de referenciais de conduta a serem seguidos e que acaba se traduzindo num modelo de "homem de verdade", num script pré-determinado de narrativa possível para a sua história pessoal.

Partindo dos discursos expressados pelos usuários foi possível averiguar que os mesmos percebem um embate entre a maneira como elaboram seus sentidos e executam suas performances de cuidado e o que é prescrito pela saúde pública. Porém, a pesquisa avaliou que sentidos de saúde e modos de cuidar de si elaborados pelos homens apenas destoam completamente daquilo que é difundido pelos serviços de saúde, pois o que se trata de "não cuidado" pela prerrogativa da saúde pública trata-se de "cuidado" sob a opinião construída pelos sentidos de saúde dos homens. Desta forma, as habilidades de cuidado dos homens não são consideradas ao passo que não se enquadram aos princípios de cuidados gerais difundidos pelas intervenções em saúde. Contudo, o que não é considerado é o potencial masculino de cuidado sob as suas representações de cuidados e seus sentidos de saúde.

A interação dos usuários com os profissionais na relação com o serviço de saúde caracterizou-se como abismal devido a diversos aspectos. Dentre eles, menciona-se a necessidade da 
escuta e do acolhimento no âmbito da unidade como própria prática de atenção em saúde, o desconforto em relatar seus problemas de saúde a profissionais que "não conversam com as pessoas" e a representação dos homens pelos profissionais, os quais alegavam que os homens são (culturalmente) fechados. A ausência de serviços básicos contribui para que os homens não se interessem pela procura de um serviço preventivo de saúde através da UBS. As vivências de demandas em saúde mental e a dificuldade de encaminhamento à rede de saúde os mobilizavam a procuras episódicas aos serviços de saúde. As necessidades financeiras e até mesmo de escolaridade influíam na busca pela saúde, alguns homens não tinham dinheiro para pagar o transporte até as instituições de referência onde receberiam atendimento especializado, outros homens apresentavam dificuldades cognitivas para compreender as prescrições médicas ou instruções básicas de saúde, mencionam-se ainda, a dificuldade de realizar consultas e exames noturnos para não prejudicar o trabalho.

As generalizações de sentidos de saúde, bem como, de performances de cuidado e às comparações do autocuidado dos homens em relação ao "ideal" autocuidado das mulheres foram muito frequentes durante as entrevistas, tanto por parte dos profissionais quanto dos próprios usuários.

Verifica-se que além da questão de gênero, a atenção básica em saúde enfrenta desafios relacionados à política, economia e sua própria sistematização. Porém, tratando do foco desta pesquisa, ressalta-se a questão de gênero como um indicador que traz à tona os déficits existentes hoje na saúde primária e suas possibilidades de intervenção. Sugere-se então, partindo da sugestão de Arilha $^{16}$, reconhecer a existência dos homens, e consequentemente, da questão de gênero nessa área não significa reivindicar aos homens um lugar de destaque, tampouco vitimá-los.

A percepção é de que a participação dos homens passa pela superação de imagens e perspectivas individualizantes e culpabilizantes, dando lugar a espaços de atenção, reconhecimento de demandas, abertura para identificar especificidades. Isto pressupõe ouvir os homens e convidá-los à participação. Porém é importante que esta escuta e este convite aconteçam também por poderem significar algo importante para estes sujeitos e não apenas porque estes tenham de ser "responsáveis".

As intervenções em saúde partem da complexidade ao considerarem o aspecto plural dos sentidos de saúde e as diversas performances de cui- dado de si elaboradas por usuários. Desta feita, discutir as dimensões que caracterizam a dinâmica das relações dos sujeitos a quem são direcionadas as políticas, faz-se um grande passo na tentativa de estruturar os serviços e as políticas de saúde sob a visão macro e micro da atenção. Afirmase que a guia adotada neste estudo, a questão de gênero, não se trata do aspecto essencial para a reestruturação das reflexões sobre saúde pública e do sistema de saúde, mas contribui para a ampliação do olhar sobre as questões intrínsecas às demandas dos usuários dos serviços de saúde.

O objetivo de compreender os sentidos de saúde e os modos de cuidar de si elaborados por homens usuários de UBS possibilitou-se a partir da escuta aos usuários e do investimento na análise do que seus discursos queriam dizer/reivindicar/afirmar/questionar/negar/etc. A unidade básica de saúde como porta de entrada do sistema de saúde em sua proposta comunitária precisa atentar aos sentidos de saúde e performances de cuidado sob a ótica da questão de gênero. Porém, ressalta-se que o fazer de tal instituição poderá ser sempre questionado a partir da avaliação do sistema de saúde. Deste modo, além da possibilidade de repensar as estratégias de saúde executadas pelas UBS, existe a necessidade de repensar os parâmetros de atenção integral à saúde do homem propostos pela política, bem como, refletir o sistema público de saúde brasileiro e suas estratégias de prevenção, promoção e intervenção. Além disso, discutir ainda a saúde coletiva faz-se de grande valia na reflexão sobre a atenção em saúde.

Reflete-se que saúde pode não precisar, necessariamente de um processo humanizatório visto que ela em si já é a própria humanidade, a saúde pode estar necessitando ser fundamentada por processos de subjetivação a partir de aspectos de gênero, culturais, históricos e sociais que consideram a construção dos sentidos de saúde e a preferência de modos de cuidados que consequentemente serão marcados nas relações das pessoas com os serviços de saúde. Compreende-se que a saúde é significada e ressiginificada cotidianamente nas relações pelas pessoas e o cuidado com a mesma pode ser de cunho autônomo por quem lhe atribui sentido. Dentre aos aspectos da atenção em saúde, elegeu-se neste estudo a questão de gênero devido ao seu caráter intrínseco nas relações e que diretamente se demonstra nas estatísticas de saúde, mas escassamente discutida nas políticas públicas.

A avaliação dos resultados aponta para, mencionando a reflexão de Gomes et al. ${ }^{17}$, a reivindi- 
cação de uma política de saúde mais integral voltada para a população masculina poderia, à primeira vista, ser tomada como uma oposição aos programas de gênero destinados à saúde da mulher. No entanto, é a partir da própria dimensão de gênero que se advoga uma abordagem também do masculino, uma vez que tanto homens quanto mulheres necessitam ser vistos em sua singularidade e em sua diversidade no âmbito das relações sociais mais amplas que estabelecem.

As interações no contexto social revelaram as masculinidades, suas relações e seus discursos, bem como, a realidade da saúde e seu característico processo de construção. Além disso, evidenciou a necessidade de refletirem-se as políticas públicas de atenção à saúde e seu papel social como cidadania. A reflexão gerada pela pesquisa propõe uma saúde construída por homens e mulheres, com suas masculinidades e feminilidades, a saúde que se torna comum ao considerar os sentidos pelas subjetividades e se desprover de generalizações. Onde o igual e o diferente não são lados e sim conjuntos de relações que se perpassam e se transformam.

\section{Colaboradores}

FA Silva e IR Silva participaram igualmente de todas as etapas de elaboração do artigo. 


\section{Referências}

1. Brasil. Ministério da Saúde (MS). Secretaria de Atenção à Saúde. Departamento de Ações Programáticas Estratégicas. Política Nacional de Atenção Integral à Saúde do Homem: Princípios e diretrizes. Brasília: MS; 2008.

2. Brasil. Ministério da Saúde (MS). Portal da Saúde. [página na Internet]. [acessado 2011 out 15]. Disponível em: http://portal.saude.gov.br/portal/saude

3. Birman J. Os sentidos de saúde. Physis 1999; 9(1):712.

4. Rateke Deise. A negação da violência como prática de liberdade: o cuidado de si como estratégia e princípio de uma formação ética. [página na Internet]. [acessado 2011 out 18]. Disponível em: www.anped. org.br/reunioes/28/textos/gt06/gt061352 int.rtf

5. Scott JW. Gênero: uma categoria útil de análise histórica. Educação \& Realidade 1995; 20(2):71-99.

6. Connel RW. Masculinities. Berkeley: University of California Press; 1995

7. Figueiredo W. Assistência à saúde dos homens: um desafio para os serviços de atenção primária. Cien Saude Colet 2005; 10(1):105-109.

8. Bardin L. Análise de conteúdo. Lisboa: Edições 70; 2006.

9. Spink MJP, organizador. Práticas discursivas e produção de sentido no cotidiano: aproximações teóricas e metodológicas. São Paulo: Ed. Cortez; 1999.

10. Fleury-Teixeira P, Vaz FAC, Campos FCC, Álvares J, Aguiar RAT, Oliveira VA. Autonomia como categoria central no conceito de promoção de saúde. Cien Saude Colet 2008; 13(Supl. 2):2115-2122.

11. Oliveira PP. A Construção Social da Masculinidade. Belo Horizonte, Rio de Janeiro: Editora UFMG, Instituto Universitário de Pesquisas do Rio de Janeiro; 2004. p. 151.
12. Lunardi VL. Problematizando conceitos de saúde, a partir do tema da governabilidade dos sujeitos. Rev. Gaúcha Enferm 1999; 20(1):26-40.

13. Campos GW, Barros RB, Castro AM. Avaliação da política nacional de promoção da saúde. Cien Saude Colet 2004; 9(3):745-749.

14. Medrado B, Lyra J, Galvão K, Nascimento P. Homens, por quê? Uma leitura da masculinidade a partir de um enfoque de gênero. Perspectivas em Saúde e Direitos Reprodutivos 2000; (3):12-16.

15. Nolasco S. O mito da masculinidade. 2a Edição. Rio de Janeiro: Rocco; 1993

16. Arilha M. Homens jovens, gênero e masculinidades In: Mac A, organizador. Perspectivas em saúde e direitos reprodutivos. São Paulo: Fundação MacArthur; 2000. p. 22-25.

17. Gomes R, Moreira MC, Nascimento EF, Rebello LE, Couto MT, Schraiber LB. Os homens não vêm! Ausência e/ou invisibilidade masculina na atenção primária. Cien Saude Colet 2011; 16(Supl. 1):983992.

Artigo apresentado em 21/04/2013

Aprovado em 28/04/2013

Versão final apresentada em 29/04/2013 